\title{
From Linear to Circular Economy: a Transaction Cost Approach to the Ecological Transformation of the Firm
}

\author{
Arne Nygaard ${ }^{1,2}$ (i)
}

Received: 24 September 2021 / Accepted: 19 January 2022 /Published online: 7 February 2022

(c) The Author(s) 2022

\begin{abstract}
Ownership and control have been the strategic focus of organizational analyses to achieve performance. The emergence of sustainable strategies has, however, confronted conventional organizational theory because performance has become a complex concept containing both social elements and environmental dimensions together with conventional economic aspects. Increased climate change, temperature risk, and environmental hazards, as well as intertwined social consequences, create a need for new theoretical insights to understand the emerging circular organization of product lifecycle networks. The ongoing climate crisis calls for new institutional approach that challenges future organizational structures. We present a framework for integrating low-carbon ecological transformation from linear to sustainable circular inter-organizational networks. The global and circular economy increases performance ambiguity, the uncertainty of eco-opportunism, information asymmetry, and transaction costs. Consequently, sustainability makes it necessary to integrate and control organizations throughout the supply chain to avoid eco-opportunism and to economize transaction costs.
\end{abstract}

Keywords Performance ambiguity $\cdot$ Eco-opportunism $\cdot$ Vertical control $\cdot$ Sustainable strategy $\cdot$ Circular organizations $\cdot$ Linear organizations

\author{
Abbreviations \\ IPCC The Intergovernmental Panel on Climate Change \\ PLC Product lifecycle \\ TCE Transaction cost economics \\ UNCED United Nations Conference on Environment and Development
}

Arne Nygaard

arne.nygaard@kristiania.no

1 Kristiania University College, Postboks 1155 Sentrum, Kirkegaten 24-26, 0107, Oslo, Norway

2 The Arctic University of Norway, Faculty of Humanities, Social Sciences and Education, Alta, Norway 


\section{Introduction}

Sustainability fuels the risk of eco-opportunism that increases the level of transaction costs in supply chains. Thus, sustainability is a serious organizational challenge in complex and global distribution systems. However, the corporate sector provides the essential entrepreneurial tools for sustainable change. Management must encourage, nurture, and safeguard sustainable development while economizing transaction costs. Failure to facilitate effective organizational structures will undermine long-term sustainable economic growth. We need to acquire more insight into how organizations can promote institutional change to support sustainable growth. Transaction cost economics (TCE) offers perspectives on the relationship between the assessment of sustainability and inter-organizational design. The evaluation of sustainable institutions cannot be isolated to a single transaction but includes the network of dyadic formations responsible for the product lifecycle (PLC) in the new circular economy $[1,2]$. A product lifecycle-institutional structure therefore requires interorganizational management from the exploration, development, and production of raw materials to the post-consumption reverse-distribution operation, primarily of unsold products, and product recirculation. Consequently, the organization of sustainability requires an inter-organizational nexus of contracts approach to product lifecycle management capable of assessing the performance of the entire life of a product [3]. Evaluation of sustainability requires that firms document, control, and monitor operations throughout the exploration and production process and along the supply chain. The extent of monitoring of distribution systems therefore exceeds intra-organizational and inter-organizational transactions in an increasingly growing and complex global business environment. However, monitoring is grounded in the contract to control the product or service functions, often in an international multi-agency network context. One example of the emerging network approach is the sportswear industry, which responded to the Greenpeace "Detox Challenge" aimed at Nike and Adidas operations in third-world countries. The campaign stopped their worldwide network contractors dumping toxic chemicals into waterways. Sustainability management that safeguards the network of firms against such eco-opportunism requires an extended level of analysis that moves from the isolated dyadic approach rooted in the classic TCE analyses of transactions to the level of network of transactions within the system of multiple economic agents (see Table 1). Consequently, the theoretical focus on dyadic analyses must be supported by macro-level aspects of product lifecycle network (PLC network) analyses in the light of the coming evolution of sustainability.

\section{Sustainable Management}

Sustainable performance is a complex three-dimensional concept leading to an ambiguous evaluation of performance. Performance ambiguity produces difficult and costly performance evaluation [4]. Consequently, sustainable performance evaluation increases costs to reveal the true value of inter-organizational exchange [5]. Sustainability not only expands performance ambiguity of the inter-organizational dyad but also increases performance ambiguity throughout the product lifecycle system in supply chains. However, received TCE theory is the framework in which to define, monitor, and enforce contracts $[6,7]$. This is a profound reasoning behind mainstream management theory, economic exchange, and strategic change. Still, management literature presents different options for 


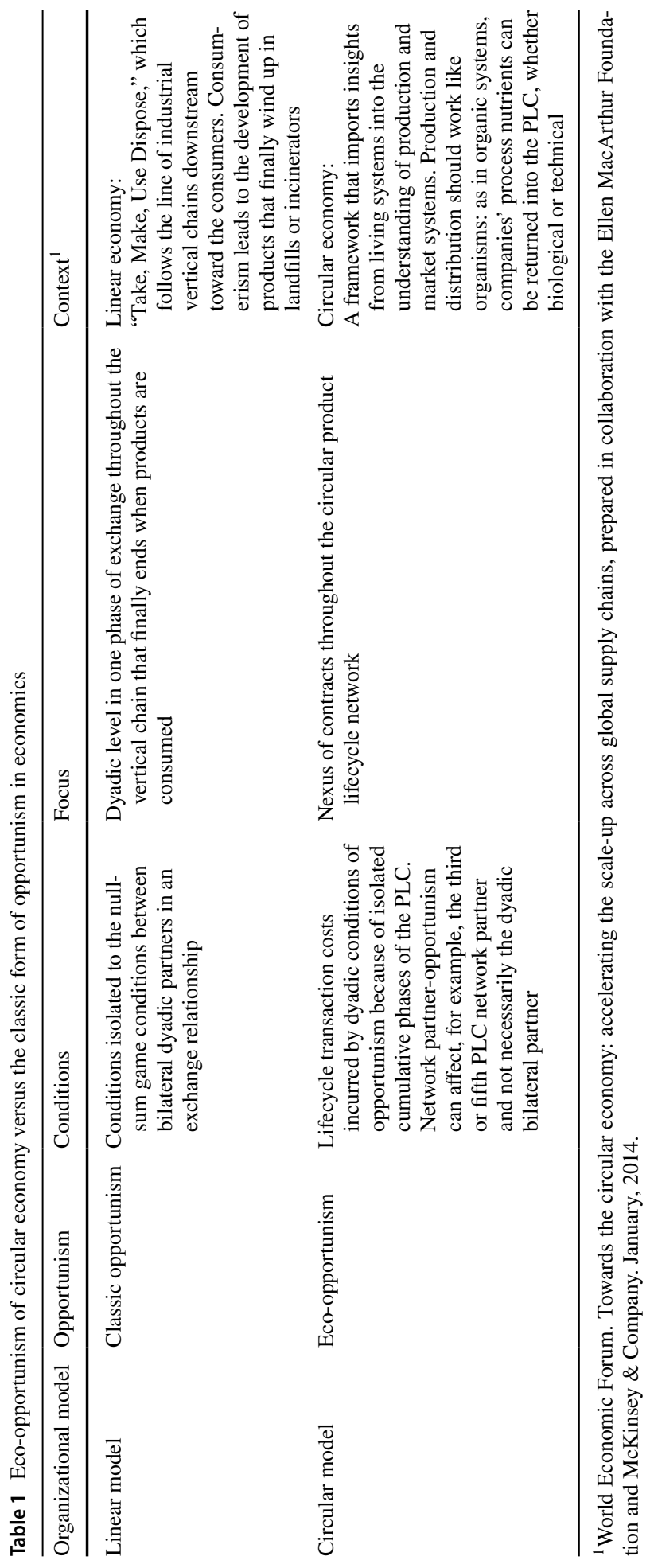


inter-organizational structures, such as franchising (the right to represent another company and brand), sales agency (the right to represent a company), or salespersons (transferring ownership of an item), to operate in the market. Thus, the traditional level of dyadic analysis avoids potential harmful eco-opportunism and the subsequent transaction costs to safeguard the interests of all parties within the product lifecycle network - consumers, stakeholders, and society in general. Received TCE theory illustrates the normative interests of the firm that might have the right to harm the environment through agent-contracts with eco-opportunistic operations. The waste markets in the computer industry lead to hazardous and dangerous recycling processes, e.g., in West Africa. Oil spill from oil exploration, development, and production along the Niger delta is another example. Increased global warming intensifies the problem of incomplete contracts among the various parties within the product lifecycle network. The new era of environmental protectionism constraints contracts and brings new contextual aspects to its theoretical offspring. Therefore, transaction cost theory must support a dyadic level of analysis with a network approach that includes combined elements of ecological, social, and financial performance. Antecedents such as cultural, political, and legal constraints add transaction costs to the PLC network. Sustainability creates performance ambiguity, both dyadic and within the entire network of organizations. Sustainability extends the level of asymmetric information in global supply chains and production systems, as the sustainable quality of products is difficult and costly to evaluate. Standardized sustainable quality through "green" brands introduces information asymmetry to the market. Without institutional frameworks that safeguard sustainability to consumers in the marketplace, markets for sustainable products will deteriorate into markets for "lemons" because consumers can no longer separate sustainable from unsustainable production [8]. The complexity of performance measurement leads to costs of evaluating the real effort in the overall product lifecycle system. Business strategy argues that outcome performance can indicate efforts whenever it is less costly to observe and evaluate. This explains, for instance, the application of sales-based monitoring systems in franchising [9]. However, sustainability breaks down the observability of both behavior-based hierarchical monitoring systems and outcome-performance monitoring systems.

TCE defines a hierarchical market as two ends of the governance continuum [10]. A hierarchical system is any form of centralized decision-making, organizational control, and monitoring systems to influence agent behavior. Sustainable management operates market-based frameworks such as quota systems (i.e., green certificates or $\mathrm{CO}_{2}$ quotas, taxes, or transferable permits). One important market-based approach is emissions trading, for instance, the European Union Emission Trading Scheme. Markets might promote solutions to environmental problems if it would be possible to internalize the negative costs of pollution or $\mathrm{CO}_{2}$ emission. When regulation of pollution to protect the environment changes the relationships between the polluting companies, it also triggers innovative processes to scale up the development of low-carbon technology to reduce the costs of pollution reduction [11]. Contracts defined through environmental regulations transfer costs to the polluter along with entrepreneurial incentives to innovate new technology. Also, countries that respond to environmental challenges by defining regulations gain a first-mover advantage because industry, rather than using incremental and linear product differentiation, will innovate to become cost leaders. In markets where it is cheap to pollute, industry will continue to differentiate instead of innovating. Furthermore, some of the most important countries in the world regarding biodiversity, eco-systems, and vulnerable environmental aspects are also among the most corrupt and probably disposed to eco-opportunism. For instance, important rainforest countries, i.e., Congo and Brazil, also have significant crime and serious corruption problems. 


\section{Organization for Sustainability}

The development of global markets cuts switching costs and provides rich information to buyers and sellers. Consequently, the new era of global markets reduces potential opportunism and transaction costs and facilitates economic performance. Sustainability, however, in the light of eco-opportunism combined with information impactedness (Table 1) would encourage more monitoring, contractual relationships, and integration. The product lifecycle perspective to achieve sustainability supports the dyadic forms of traditional opportunism with a new formula of "eco-opportunism": the combined ecological, social, and financial "self-interest-seeking behavior with guile" [10]. We extend the opportunism concept to include hidden actions and information to breach financial, social, and ecological dimensions of the product lifecycle network of contracts (Table 1).

\section{From Opportunism to Eco-opportunism}

The dyadic level of analysis is a necessary but not sufficient condition for sustainable management. The dyadic concept incorporates the potential exploitation of asymmetrical information within the bilateral system. Opportunism represents the calculated behavior behind hidden information. The classic concept of opportunism includes efforts to deceive the other party to the transaction (Table 1). In the conventional TCE model, we assume that more opportunism is involved in transactions under more complex conditions. Opportunism reflects conflicts of interests between parties in the relationship, and while opportunism relates to dyadic relationships, eco-opportunism relates to all information asymmetry within the entire product lifecycle network of economic agents (Table 1). Eco-opportunism comprises double-sided moral hazards in the overall product lifecycle system [12] and relates not only to the single dimension of economic performance but also includes indices into a three-dimensional sustainability concept. The complexity of the threefold sustainability concept produces information asymmetry and encourages the development of the eco-opportunism.

\section{Transaction Costs of Eco-opportunism}

The classic TCE model proposes that transaction costs following potential bilateral opportunism affect performance ex post. The survival of the most efficient institutional structures indicates that contracts affect transaction costs and performance [13]. Consequently, the dyadic contract nurtures the long-time survival of the product lifecycle-institutional structure. The costs of alternative inter-organizational structures affect performance [14]. The economic interests of the principal are manifested in the inter-organizational design and ex post performance [15]. Sustainability, however, is connecting the overall economic interests of all parties along the product lifecycle-institutional structure in a supply chain and production system (Table 1) [16]. Eco-opportunism therefore affects both levels of analysis and the conventional dimensions of transaction costs [17]. So, long-term survival is no longer solely a question of the economic organization that produces financial performance but requires that the product lifecycle-institutional structure includes measurable sustainable performance. Figure 1 illustrates that eco-opportunism increases potential transaction 
Fig. 1 Costs of eco-opportunism transforming linear organizations to circular organizations stimulating more integration and control

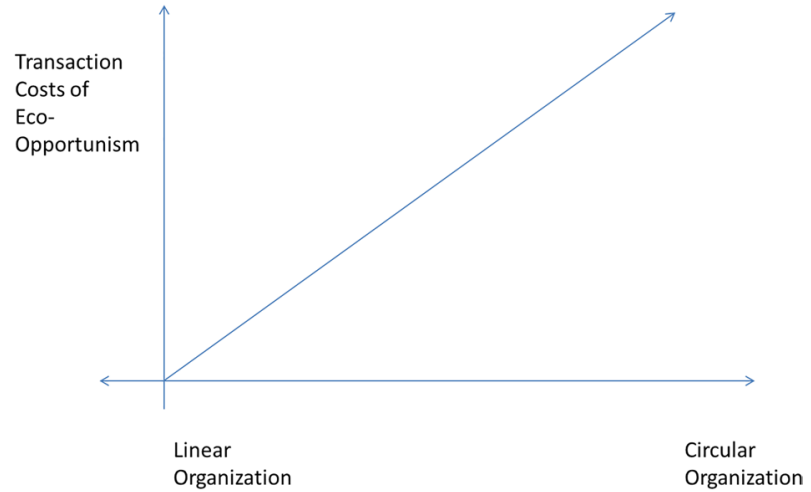

costs substantially when the network of multiple organizations in a supply chain must coordinate transactions to achieve circularity. A circular economy, for instance, farm-to-fork, is complex, difficult to control and costly to coordinate, and conventional linear management hesitates to change [18]. Transaction costs such as bargaining, monitoring, maladaptation, free-riding, and shirking costs are important problems that the green transition to a circular economy must face in supply chains. A circular organization of transactions that involve all organizations in a supply chain results in higher transaction costs to safeguard sustainability (Fig. 1). The linear organization, however, protects the interests only of the two parties in a transaction with little or no attention to social or environmental aspects.

\section{Uncertainty}

Reacting to the Intergovernmental Panel on Climate Change, IPCC, "climate-related risks involve decision-making in a changing world, with continuing uncertainty about the severity and timing of climate-change impacts and with limits to the effectiveness of adaptation" [19]. The driving force in the process that develops transaction costs is the "horizon of opportunism" [10], which is influenced by external uncertainty in the business environment. The architecture of the product lifecycle-institutional structure should protect the organizational network in a supply chain against such hidden and costly "self-interest-seeking behavior" in the system [10]. The ownership to the "product" will however accumulate all external costs related to its lifecycle in the hands of the principal. Not only will $\mathrm{CO}_{2}$ emissions, pollution, and social dimensions accumulate costs related to the production, but the sustainability concept will also affect the costs of opportunism at all stages of the product lifecycle process. The behavioral uncertainty is not connected only to the inter-firm relationship but also to the entire network. Sustainable management directs a strong focus on the sustainable uncertainty provided by the stakeholder groups surrounding the product lifecycle network. A myriad of interest groups engages in various aspects of the product lifecycle, and the product lifecycle-institutional structure must evaluate the potential risk they present. The defensive approach to see only the framework presented by the local legal system is no longer sustainable. Contractors or sub-contractors are strong contributors to the supply chain structure, but they may have private interests in a complex world of free markets. The Nestle "horsemeat" scandal in 2013 showed that intermediate markets within the product lifecycle-institutional structure could be invaded by opportunistic 
activity operating within the production under the Nestle brand that imposed transaction costs on firms at the other end of the institutional distribution network system. H\&M, Gap, and Adidas were focused on because of worker rights in production firms in Cambodia. In 2013, a building collapsed in Bangladesh, killing more than 1100 people inside who were producing clothes for eco-certified brands such as Tesco, Walmart, and Benetton. Established brands and firms are no longer hidden from the transaction costs of eco-opportunism by contractors, sub-contractors, or distant partners at the other end of their global institutional network.

\section{Theoretical Implications}

The organization of sustainability of operations and transactions in a product lifecycle system is related to the ability to monitor and evaluate performance and to determine the true value of the objects of exchange [20]. Sustainability is a complex performance concept and is therefore costly to evaluate because of its multidimensionality and the technologies involved. When a company rewards sustainability performance and punishes poor sustainability, TCE theory provides some analytical implications. As the performance ambiguity of sustainability outcomes becomes more difficult to evaluate, markets fail because transaction costs exceed the costs of bureaucratic solutions [10]. Transaction cost theory therefore suggests that the complexity of performance evaluation leads to increased transaction costs and thus more inter-organizational control [21]. Previous empirical research has revealed that as unobservable or un-measurable non-sales activities become important, firms choose to integrate their operations [22]. Therefore, sustainable performance leads to greater integration of the partnerships in the supply chains [23].

\section{Market Failures, Eco-specific Assets, and Natural Resources}

Historically, market failures due to resource scarcity combined with specific investments have encouraged vertical control and integration. The "Seven Sisters" that controlled 85\% of the oil market prior to the 1973 oil crisis were all vertically integrated [24, 25]. Climate change will, however, continue to produce market failures that challenge the conventional organizational structure within the product lifecycle. Climate change produces market failures and jeopardizes specific investments that firms need to safeguard.

Linear business models are often focused on activities downstream toward the consumers. The conventional motivation is the final transaction between the business and its consumers, and the conventional business model reflects a linear process in the supply chain toward consumption that ends in junkyards or ovens. It reflects firms as a coalition of vertical organizational interests bringing products from producer to consumer. The linear model has been described as a "marketing channel" [26], or a network [27] where organization related to post-consumption has not been a strategic issue for firms. The conversion from linear to circular institutional structures is evident in the electricity power industry, as we can see in Table 2. Electricity companies' conversion to a circular economy is reflected in the fuel mix between coal (non-renewable) and renewable energy sources such as hydro, wind, solar, or other circular energy sources. Enel SPA, one of the top circular electricity generation companies, has $33 \%$ of its total fuel as renewable, while another large electricity company, RWE AG, is fueled $61 \%$ by coal, and Dominion Resource Inc. produces only 
Table 2 The percentage of renewable energy (circularity) and coal (linearity) of nine of the largest international power-producing companies 31.12.2014

\begin{tabular}{llll}
\hline Electric power company & $\begin{array}{l}\text { Circular (renew- } \\
\text { able) percentage* }\end{array}$ & $\begin{array}{l}\text { Linear (coal) } \\
\text { percentage }\end{array}$ & Other** $^{* *}$ \\
\hline Enel SpA & 33 & 29 & 38 \\
SSE PLC & 19 & 56 & 24 \\
GDF Suez & 18 & 22 & 59 \\
NextEra, Inc & 17 & 4 & 80 \\
E.ON SE & 12 & 32 & 56 \\
Electricite de France & 11 & 9 & 80 \\
Duke Energy Corp & 9 & 40 & 52 \\
RWE AG & 6 & 61 & 32 \\
Dominion Resources Inc & 3 & 26 & 71 \\
\hline
\end{tabular}

${ }^{1}$ Norges Bank 2014 Responsible Investment Government Pension Fund Global report, p. 61.

*Includes, among others, water, solar, geothermal, and wind power.

**Includes, among others, nuclear, and oil- and gas-based power generation.

$3 \%$ renewable energy. Like the tobacco industry 50 years before, the electricity generation industry is forced by stakeholders and investors to change their business models from linear to circular organizational structures. For example, institutional investors, such as the world's largest investment fund The Government Pension Fund of Norway, have now decided to move away from coal, and the second largest investment fund in the USA, The California State Teachers Retirement System, has started to evaluate the same.

Another example of circular strategy is McDonalds, which fuels its trucks with its own cooking oil. Unilever is committed to changing from a linear to a circular organization and intends to "reduce environment footprint and increase positive social impact" and to "double sales and increase long-term profit" [28].

The circular economy is a concept imported from life sciences further to understand production and market systems in an organizational network. The core idea is that business systems imitate organic mechanisms in nature [29]. The circular organizational model is technically prepared and designed to exploit waste produced during the PLC and incorporate it back into the value chain. Biological waste should be cultivated to circulate it back into the environment. The other dimension of a circular organizational model involves the technical components. Technical components, metals, and toxic or other recyclable elements should be prepared to re-enter the production and distribution system. New regulations in the EU hold the car and electronics companies accountable for the lifecycle of their products. Furthermore, by removing biological and technical components (e.g., minerals), it is also possible to eliminate the risk of toxic elements arising from the product lifecycle.

\section{Toward an Ecological Theory of the Firm}

We argue that only a one-dimensional dyadic perspective will marginalize the future relevance of transaction cost theory. The traditional concepts of the received theory must be brought into an ecological context to explain the current development of future institutional structures. Sustainability causes new forms of market failures as well as market contexts 
based on social and environmental dimensions. A vital new approach adds two essential aspects to received theory: (1) a macro product lifecycle level of strategic analysis of institutional networks, and (2) a triple dimensional performance concept that includes economic, ecological, and social elements. Based on this understanding of the new context, we develop seven propositions that frame some relevant empirical efforts for strategic analysis based on transaction cost theory as portrayed in Fig. 2.

\section{Sustainability and Performance Ambiguity}

We propose that the multidimensional concept of sustainability increases the level of performance ambiguity, which is the difficult and complex measurement of exchange in question $[5,30]$. Despite formidable work to measure and analyze sustainable development, the three basic dimensions of economic, environmental, and social conditions have been criticized [31]. Sustainable strategies relate to the triple bottom-line performance of ecological, social, and economic dimensions that together produce a vague and complex concept [32]. To systematically find and apply adequate information to assess sustainable strategies is

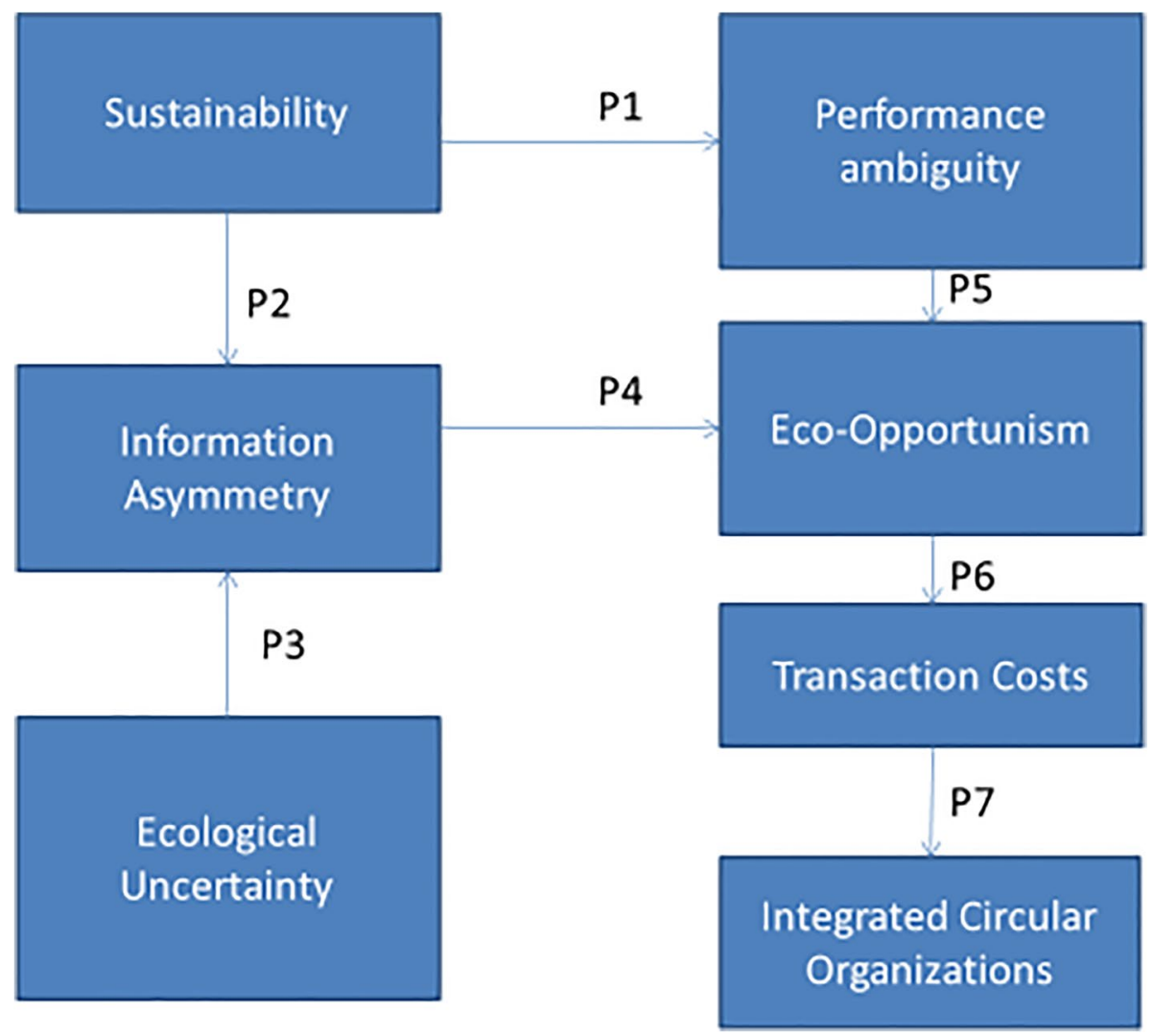

Fig. 2 The ecological theory of organizing the transition from linear to circular economy 
difficult. Sustainability therefore leads to increased performance ambiguity. Thus, we propose that:

P1: Sustainability increases the level of performance ambiguity.

\section{Information Asymmetry}

Sustainable management is now a crucial element of conventional business wisdom. However, simultaneously, there is a problem that sustainable production is based on information from the entire network of economic agents within the product lifecycle network, from exploration to recycling in a supply chain. The owner of a brand in the fashion market cannot focus only on the market context but needs information about recycling systems as well as the social aspects of production, freshwater input, and carbon footprint. Sustainability creates a new dynamic, complex, and uncertain demand for information throughout the product lifecycle network. Global sourcing has further complicated the flow and validation of information. Therefore, sustainability drives an ongoing process of information asymmetry. The agents within the product lifecycle network gain information superiority through the sustainable management strategy. We therefore propose that:

P2: Sustainability increases the level of asymmetric information throughout the product lifecycle network of economic agents.

\section{Ecological Uncertainty}

Ecological uncertainty is one of the driving components of the ecological theory of organizations. The river Nile is an ancient example of how uncertainty affects institutions. Egypt is the oldest and most stable civilization because of long-standing stable access to sustainable freshwater through the river Nile. The uncertain water supply upstream in the nine other countries of the Nile delta has produced environmental uncertainty, resulting in problems for the stability of governance systems. Egypt therefore has been portrayed as a stable institutional structure, while the civilizations upstream, although culturally similar, has historically been unstable [33]. Several external environmental factors contribute to stability or uncertainty.

Increases in ocean temperatures and greater weather variations will change substantially the physical conditions of infrastructures within inter-organizational networks. The speed and impact of change in the business environment varies between industrial sectors and geographical areas. Inter-organizational responses to ecological uncertainties must face "the dynamics of vulnerability and exposure and their linkages with socioeconomic processes, sustainable development, and climate change" [19] emphasized by the IPCC [34]. The IPCC considers five crucial ecological risks, as presented in Table 3. Ecological risks produce inter-organizational response to uncertainty. IPCC [19] dimensionalizes the ecological risks to which inter-organizational networks must actively respond: (1) unique and threatened systems, (2) extreme weather events, (3) distribution of impacts, (4) global aggregate impacts, and (5) large-scale singular events. The development of integrated global inter-organizational networks leads to ecological uncertainty that single agents in this system must deal with. 
Table 3 Intergovernmental Panel on Climate Change, IPCC, [19] risk dimensions of ecological uncertainty

(1) Unique and threatened systems: Some unique and threatened systems, including ecosystems and cultures, are already at risk from climate change (high confidence).

The number of such systems at risk of severe consequences is higher with additional warming of around $1{ }^{\circ} \mathrm{C}$. Many species and systems with limited adaptive capacity are subject to very high risks with additional warming of $2{ }^{\circ} \mathrm{C}$, particularly Arctic-sea-ice and coralreef systems

(2) Extreme weather events:

Climate change-related risks from extreme events, such as heat waves, extreme precipitation, and coastal flooding, are already moderate (high confidence) and high with $1{ }^{\circ} \mathrm{C}$ additional warming (medium confidence). Risks associated with some types of extreme events (e.g., extreme heat) increase further at higher temperatures (high confidence)

(3) Distribution of impacts:

Risks are unevenly distributed and are generally greater for disadvantaged people and communities in countries at all levels of development. Risks are already moderate because of regionally differentiated climate change impacts on crop production in particular (medium to high confidence). Based on projected decreases in regional crop yields and water availability, risks of unevenly distributed impacts are high for additional warming above $2{ }^{\circ} \mathrm{C}$ (medium confidence)

(4) Global aggregate impacts:

Risks of global aggregate impacts are moderate for additional warming between 1 and $2{ }^{\circ} \mathrm{C}$, reflecting impacts to both Earth's biodiversity and the overall global economy (medium confidence). Extensive biodiversity loss with associated loss of ecosystem goods and services results in high risks around $3{ }^{\circ} \mathrm{C}$ additional warming (high confidence). Aggregate economic damages accelerate with increasing temperature (limited evidence, high agreement), but few quantitative estimates have been completed for additional warming around $3{ }^{\circ} \mathrm{C}$ or above

(5) Large-scale singular events:

With increasing warming, some physical systems or ecosystems may be at risk of abrupt and irreversible changes. Risks associated with such tipping points become moderate between 0 and $1{ }^{\circ} \mathrm{C}$ additional warming, due to early warning signs that both warm-water coral reef and Arctic ecosystems are already experiencing irreversible regime shifts (medium confidence). Risks increase disproportionately as temperature increases between 1 and $2{ }^{\circ} \mathrm{C}$ additional warming and become high above $3{ }^{\circ} \mathrm{C}$, due to the potential for a large and irreversible sea level rise from ice sheet loss. For sustained warming greater than some threshold, 35 near-complete loss of the Greenland ice sheet would occur over a millennium or more, contributing up to $7 \mathrm{~m}$ of global mean sea level rise

Organizations must handle ecological uncertainties that affect the complexity and dynamics of the organizational structure [35]. Ecological uncertainty is an external force that constrains the availability of resources and affects the internal power structures in organizations, which then strive to absorb and neutralize ecological uncertainty within the global network of exchange [36]. Internationalization of inter-organizational networks therefore exposes supply chains to the serious effects of climate change. The global nature of sourcing and production of components intensifies the impact of climate change. As we have seen during the flood in Thailand in 2011, the distribution chains of Toyota, Honda, Samsung, and Lenovo were hit, leading to negative downstream effects in their supply 
chains. Investments in specific assets must consider not only potential behavioral opportunism but also the changing external conditions caused by climate change and resource depletion followed by potential eco-opportunism. The lack of a sustainable product lifecycle structure leads to eco-system loss and resource depletion because of eco-opportunism. Ecological uncertainty may lead to irreversible damage to biological diversity and the extreme long-term climate effects of $\mathrm{CO}_{2}$ emissions. Uncertainties change the factual aspect of the inter-organizational relationships and contracts throughout the networks. Both implicit and explicit contracts become incomplete or obsolete. The IPCC Report on climate change [19] Impacts, Adaptation, and Vulnerability (part 2) pointed out that ecological uncertainty leads to limited evidence and that "Studies estimating the global cost of adaptation are characterized by shortcomings in data, methods, and coverage." Ecological uncertainty therefore develops informational impactedness that decision-makers must overcome [37]. Consequently, we propose that:

P3: Ecological uncertainty increases the level of asymmetric information throughout the product lifecycle network of economic agents.

\section{Information Asymmetry and Eco-opportunism}

Williamson [37] proposed that information asymmetry fosters opportunism. The risk of self-interest-seeking behavior is entangled with difficulties and complexity in observing an agent's behavior. When contexts of information asymmetry appear, there is a behavioral risk of opportunism. However, eco-opportunism may characterize many markets. The "markets for lemons" [27] such as "greenwashing" might be a typical eco-opportunism situation under information asymmetry. For instance, the "horsemeat scandal" in 2013 illustrated eco-opportunism under a "market for lemons" situation. Beef sold in Europe contained, in some cases, $100 \%$ horsemeat. The scandal revealed the lack of traceability in the supply chain. One illustration of eco-opportunism also includes "show-room" factories built to fool other companies in the supply chain that production is sustainable. Ecoopportunists show clean production facilities with healthy and happy employees, while the production takes place somewhere else. We therefore conclude that sustainable strategies are affected by informational asymmetry through the threat of eco-opportunism:

P4: Informational asymmetry increases the incentives for eco-opportunism in supply chain networks.

\section{Performance Ambiguity and Eco-opportunism}

Performance ambiguity encourages eco-opportunism [5]. Difficult, complex, heterogeneous, and multidimensional indices of sustainable performance measures will motivate ecoopportunism even more. As early as in the United Nations Conference on Environment and Development, UNCED, the UN emphasized the essential role of the development of sustainable performance indications that "improve the information basis for decision-making at all levels" [38]. Thereafter, there have been reported huge efforts into the development of performance measurement indications. The compendium of sustainable development indication initiatives includes more than 500 performance indication measures of 
sustainable development [39]. The ambiguous and inconsistent application of performance measurement indications creates a window that encourages eco-opportunism. Therefore, we propose:

P5: Performance ambiguity increases eco-opportunism.

\section{Eco-opportunism and Transaction Costs}

Eco-opportunism is the self-interest-seeking behavior that has collective effects on the entire product lifecycle network in the shadow of sustainable development. Greenwashing brands, or companies, are well known examples of eco-opportunistic behavior. The global emission from fossil energy companies responsible for 9.8 gigatons of carbon emissions in 2013 did not constrain them from communicating sustainable behavior through "green" brands, web pages, and other "green" initiatives. However, eco-opportunism has attracted more negative attention from non-governmental organizations, the media, and society in general. Thus, economic agents tend to monitor and control their inter-organizational contracts to safeguard their environmental, social, and economic preconditions. Specialist consultancies and agencies monitor and control sustainable development upstream and downstream in the product lifecycle network. Sustainability creates the potential for ecoopportunism that is costly to monitor and control. We therefore propose that:

P6: Eco-opportunism leads to increased transaction costs.

\section{Transaction Costs and Transition from Linear to Circular Institutional Structures}

Transaction costs are related to the level of control existing through the institutional structure [5]. Transaction costs are the costs of organizing and verifying the true value of interorganizational exchange [10] within the product lifecycle-institutional structure. When costs of organizing exchange in the market exceed those of bureaucratic exchange, management strategy chooses more integrated institutional alternatives. Monitoring, bargaining, maladaptation, shirking, and free-riding costs are all contract-related costs affected by sustainable strategies [17]. Sustainability manifests that the transaction costs of organizing the overall lifecycle structure will determine the institutional structure. Low transaction costs of assessing the true value of the sustainable exchange result in less need for interorganizational control. Sustainability, however, produces a more complex situation where the value of the exchange in question is more costly to assess than is the more conventional dyadic exchange. Consequently, the parties' involvement in monitoring, bargaining, and coordination increases. These transaction costs affect the institutional structure of the overall product lifecycle, and so the increased transaction costs associated with circular economy should therefore lead to greater integration and control [10]. Thus, we propose that:

P7: Transaction costs related to coordination and control lead to increased integrated circular organizations. 


\section{Conclusions}

Future contact with, impact of, and responses to social and environmental systems are substantial. Thus, it is crucial to investigate the interactive effects between social, environmental, and financial systems, and potential uncertainties. Inter-organizational lifecycle networks of firms are crucial catalysts in promoting and developing a circular economy. Management research must draw attention to the circular interaction between human and environmental systems. The linear business model is obsolete, outdated, and simplistic, and is a dangerous instrument to solve future environmental challenges, as is the conventional linear management theory of the firm. Strategic implications based on transaction cost theory should extend the level of analysis from dyads to institutional supply chain networks. Through the lens of TCE, we have analyzed how the institutional organization safeguards the parties against the potential risk of eco-opportunism. Transaction costs caused by increased performance ambiguity are related to the new concept of sustainability.

The recent developments of environmental hazards concerning biological eco-systems, water, resources, the atmosphere, and related social problems are closely interwoven with the strategic problems of the institutional formation of organizations. Specific sustainable assets must fit social structures, the environment, and the economy, and should form future circular organizations. The product lifecycle network should become the new level of forthcoming strategic analysis. We conclude that TCE presents a constructive approach to the analysis of the strategic formation of institutional structures that can respond to ecoopportunism, eco-uncertainty, information asymmetry, transaction costs, and performance ambiguity. It is urgent to redesign organizational networks into circular institutional structures to facilitate low-carbon growth. Climate-affecting gases can be long-lived and difficult to reduce, biological diversity reductions are irreversible, and social developments are crucial catalytic instruments to develop a sustainable world. I hope this theoretical review inspires management research in circular and sustainable economy.

Acknowledgements The author thanks the chief editor, Dr. Alexandros I. Stefanakis, the reviewers, Professor Robert Dahlstrom, Professor Ragnhild Silkoset, and Professor Harald Biong, and colleagues at Kristiania University College, Norwegian School of Economics, The Arctic University of Norway, and at the University of Oslo for their comments and insights related to this project. A previous version of this paper was presented at the Conference in 2017 on "Sustainable business models? Historical and institutional dynamics of corporate (ir)responsibility" at the University of Oslo, Faculty of Law, at the 2018 FIBE Conference at the Norwegian School of Economics, and in a Tabula Gratulatoria in connection with the celebration of Professor Torger Reve.

Funding Open access funding provided by Kristiania University College.

Code Availability Not applicable.

\section{Declarations}

Conflict of Interest The author declares no competing interests.

Open Access This article is licensed under a Creative Commons Attribution 4.0 International License, which permits use, sharing, adaptation, distribution and reproduction in any medium or format, as long as you give appropriate credit to the original author(s) and the source, provide a link to the Creative Commons licence, and indicate if changes were made. The images or other third party material in this article are included in the article's Creative Commons licence, unless indicated otherwise in a credit line to the material. If material is not included in the article's Creative Commons licence and your intended use is not permitted by statutory regulation or exceeds the permitted use, you will need to obtain permission directly from the copyright holder. To view a copy of this licence, visit http://creativecommons.org/licenses/by/4.0/. 


\section{References}

1. Opara LU (2003) Traceability in agriculture and food supply chain: a review of basic concepts, technological implications, and future prospects. J Food Agric Environ, 1 (1), 101-106. https://agris.fao.org/ agris-search/search.do?recordID=FI2016100260

2. Kumar S, Putnam V (2008) Institutional perspectives on supply chain management. Int J Prod Econ 115(2):305-315

3. Stark J (2011) Product lifecycle management. Springer Verlag, London

4. Holmstrøm B (1979) Moral hazard and observability. Bell J. Econ, 10(1), 74-91. https://personal. utdallas.edu/ nina.baranchuk/Fin7310/papers/Holmstrom1979.pdf

5. Ouchi WG (1980) Markets, bureaucracies, and clans. Adm. Sci. Q, 25 (1),129-141. https://www. jstor.org/stable/2392231

6. Demsetz H (1967) Toward a theory of property rights. Am Econ Rev, 57(2) (May), 347-359. https://edisciplinas.usp.br/pluginfile.php/4125701/mod_resource/content/1/demsetz.pdf

7. Yonai DK (2007) Conceptions of property rights and norms. Const. Political Econ, 18(3), 161-176. https://link.springer.com/article/10.1007/s10602-007-9021-5

8. Akerlof GA (1970) The market for "lemons": quality uncertainty and the market mechanism. Q J Econ 84(3):488-500

9. Shane S (1998) Explaining the distribution of franchised and company-owned outlets in franchise systems, J Manage, 24 (6) (Nov-Dec), 717-728.

10. Williamson OE (1985) The economic institutions of capitalism. The Free Press, New York

11. Porter ME van der Linde C. (1995) Toward a new conception of the environment-competitiveness relationship. J Econ Perspect, 9(4), 97-118. https://www.aeaweb.org/articles?id=10.1257/jep.9.4. 97

12. Bhattacharyya S, Lafontaine F. (1995) Double-sided moral hazard and the nature of share contracts. Rand J Econ, 26(4) Symposium on the Economics of Organization (Winter, 1995) 26(4), 761-78. https://www.jstor.org/stable/2556017

13. Alchian A (1950) Uncertainty, evolution, and economic theory. J Polit Econ, 58 (3), 211-221. https://www.journals.uchicago.edu/doi/abs/10.1086/256940

14. Jensen MC Meckling WH (1976) Theory of the firm: managerial behavior, agency costs and ownership structure. J Financ Econ, 3 (4), 305-360. https://www.sciencedirect.com/science/article/pii/ 0304405X7690026X

15. Milgrom P, Roberts J (1992) Economics, organization and management. Prencice Hall Inc, Englewood Cliffs, N.J.

16. Lahti T, Wincent J, Parida V (2018) A definition and theoretical review of the circular economy, value creation, and sustainable business models: where are we now and where should research move in the future? Sustainability 10:2799. https://doi.org/10.3390/su10082799

17. Dahlstrom R, Nygaard A (1999) An empirical investigation of ex post transaction costs in franchised distribution channels. J Marketing Res, 36(2) (May),160-170. https://journals.sagepub.com/ doi/full/10.1177/002224379903600202?casa_token=MmoalYqF2tIAAAAA/3ACZ2YDq6LPSSUr 9axxmyAaFeXOK1xR-wmnvyyWYCEIOGYTgKnrLzzEiVhVGqdaDmdvcSnUZ8BtryKcA

18. Hahn T, Preuss L, Pinkse J, Figge F (2014) Cognitive frames in corporate sustainability: managerial sensemaking with paradoxical and business case frames. Acad Manage Rev 39(4):463-487. https://doi.org/10.5465/amr.2012.0341

19. Climate Change (2014) Impacts, adaptation, and vulnerability. Part A: global and sectoral aspects. Contribution of Working Group II to the Fifth Assessment Report of the Intergovernmental Panel of Climate Change, IPCC.

20. Jones GR (1984) Task visibility, free riding, and shirking: explaining the effect of structure and technology on employee behavior. Acad Manage Rev, 9(4), 684-695. https://journals.aom.org/doi/ abs/10.5465/amr.1984.4277404

21. Kim SK Mcfarland RG Kwon S Son S Griffith DA (2011) Understanding governance decisions in a partially integrated channel: a contingent alignment framework. J Marketing Res, 48(3) (June):603-616. https://journals.sagepub.com/doi/full/10.1509/jmkr.48.3.603?casa_token=Kka8k 1JkcckAAAAA/3A1B2yyg1TTN-I4JOoW2HcpJaNVgqXaK_BGDZDhV5kfhQ7w8QtFkVn1GGy zFw8W7RGI_KU1qrxM-cbOw

22. Anderson E (1985) The salesperson as outside agent or employee: a transaction cost analysis. Market Sci, 4 (3):234-254. https://pubsonline.informs.org/doi/abs/10.1287/mksc.4.3.234

23. Stump RL Heide JB (1996) Controlling opportunism in industrial relations J Marketing Res, 33(4) (November), 431-441. https://journals.sagepub.com/doi/abs/10.1177/002224379603300405 
24. Sampson A (1977) The Seven Sisters; the great oil companies \& the world they shaped. Coronet Books, London

25. Ndubisi NO Nygaard A Chunwe NG (2020) Managing sustainability tensions in global supply chains: specific investments in closed-loop technology vs 'blood metals'. Prod Plan Control, 31(1112), 1005-1013. https://www.tandfonline.com/doi/full/10.1080/09537287.2019.1695921?casa_ token=PaVSoPDA5GoAAAAA/3AbhKZWDQKqO6gIZzJgvKEh2vCpWgkBKuPtYO4VdtGHwS 1Y54pLIx-3zY_twTTIBUYFRnJcpXB-Kmi3qZUhw

26. Kotler P Keller KL (2009) Marketing management. Upper Saddle River, N.J: Pearson Prentice Hall, Hoboken, New Jersey.

27. Achrol RS Kotler P (1999) Marketing in the network economy. Fundamental issues and directions for marketing, J Marketing, 63 (4), 146-163. https://journals.sagepub.com/doi/full/10.1177/0022242999 0634s114?casa_token=V-AElUEnewMAAAAA/3APDw5NyEg4qJQLC0sjkseXWJfd0YR4GpGe V7Pq6MGT_kaClRQpvwISRxw_t_gglOvvzzEbCcVxZlmfA

28. The Economist (2014) August 9th in search of the good business. p.51.

29. Stahel W (2010) How to measure it, the performance economy, 2nd edn. Palgrave MacMillan, London, UK

30. Bowen DE Jones GR (1986) Transaction cost analysis of service organization-customer exchange, Acad Manage Rev, 11(2):428-441. https://web.p.ebscohost.com/ehost/pdfviewer/pdfviewer?vid=0\& $\mathrm{sid}=\mathrm{fd} 7 \mathrm{f} 245 \mathrm{~b}-6307-48 \mathrm{fc}-\mathrm{bc} 48-\mathrm{f} 7 \mathrm{c} 774839 \mathrm{c} 20 \% 40 \mathrm{redis}$

31. Böhringer C Jochem EP (2006) Measuring the immeasurable: a survey of sustainable indices. Discussion paper \# 06-073, Zentrum für Europäische Wirtschaftsforschung GmbH.

32. Phillis YA Andriantiatsaholiniaina LA (2001) Sustainability: an ill-defined concept and its assessment using fuzzy logic. Ecol Econ, 37(3), 435-456. https:/www.sciencedirect.com/science/article/ pii/S0921800900002901?casa_token=c4evn4w61S4AAAAA:eogxI2rfSh0_49dgSBjMWbdge-eAYA1 ck8Kez1rM1DAE8Jvxw9WJTW2hlNYpxBiSwN594d7kT4Y

33. Mikhail A (2011) Nature and empire in Ottoman Egypt: an environmental history. Cambridge University Press. New York City, New York

34. Zakour, MJ Mock NB Kadetz, P (2018) Editors' introduction: the voices of the barefoot scholars. In Creating Katrina, rebuilding resilience (pp. 3-23). Butterworth-Heinemann.

35. Thompson JD (2003) (1967) Organizations in action: social science bases of administrative theory (with a new preface by Mayer N. Zald and a new introduction by W. Richard, Scott. Transaction Publishers, New Brunswick, New Jersey

36. Pfeffer J, Salancik GR (1978) The external control of organizations: a resource dependence perspective. NY, Harper and Row, New York

37. Williamson OE (1975) Markets and hierarchies: analysis and antitrust implications. The Free Press, New York, N.Y

38. United Nations Conference on Environment and Development, Rio de Janeiro, Brazil, 3-14 June 1992. UNCED, 1992, Agenda 21, Ch. 40.

39. Parris TM, Kates RW (2003) Characterizing and measuring sustainable development. Annu Rev Environ Res 28(13):1-28 